\title{
Use of HCI Components into IT Courses
}

\author{
Anrieta Draganova and Patrick Doran
}

\begin{abstract}
This paper presents guidelines for the adoption of Human-Computer Interaction (HCI) subject materials at an undergraduate level of an Information Technology (IT) program. The authors develop a rationale for integrating HCI-focused materials into Information Technology (IT) curriculum. Lists of important HCI instructional materials and skills that undergraduate learners could use to enhance their knowledge for effective professional careers in the industry are provided. Several approaches for incorporating HCI components into existing and new IT courses are discussed. Based upon the authors experience and knowledge of HCI-focused courses, there are suggestions for applying cognitive pedagogy for teaching undergraduate HCI courses where experience and knowledge support the theory.
\end{abstract}

Index Terms-Human factors, human computer interaction (HCI), IT course program, cognitive pedagogy.

\section{INTRODUCTION}

With the rapid evolution of technology, Human-Computer Interaction (HCI) has become an important component of Information Technology (IT). Human-Computer Interaction is interdisciplinary in context and its factors are fundamental and critical. HCI is applied by educators, researchers, and professionals from fields such as information technology, computer science, management, cognitive psychology, and human performance engineering. Gerlach and Kuo [1] stated a need for researchers to study human behavior in the IT research. Curzon, Ruksenas, and Blandford [2] linked a cause of IT failures to a lack of focus on the socio-human aspects of system use.

HCI goals are connected to the achievement of IT system functionality, usability, enhanced user experience, and the support of user interaction effectiveness. The achievement of an effective individual and organizational interaction between the system and its users is made possible by the work of knowledgeable developers and managers. These play the role of facilitators among task contexts, users, and environments in which the systems is used. The role of educators focuses on preparing the next generation of developers, managers, and providers of IT systems with skills and knowledge in the field of HCI. To meet the needs of industry, many IT educational programs incorporate HCI courses into their undergraduate and graduate IT curricula. Santos [3] supported the integration of HCI courses in graduate programs, focusing on the importance of $\mathrm{HCI}$ to e-commerce and web development solutions.

Manuscript received November 12, 2012; revised January 15, 2013.

A. Draganova is with The George Washington University, Washington D.C. USA (e-mail: anri@gwu.edu).

P. Doran is with Zayed University, Abu Dhabi, United Arab Emirates. (e-mail: Patrick.Doran@zu.ac.ae).
The objectives of this paper are to establish a case for integrating $\mathrm{HCI}$ courses in both the graduate and undergraduate IT programs and to present approaches that integrate $\mathrm{HCI}$ courses into new or existing IT curricula. Human Computer Interaction (HCI) is discussed from the constructive perspective [4]. It focuses on aspects of the technology, human skills and abilities, and the interactions between them that are central for understanding not only the task that humans are to undertake, but also the conditions under which the interaction occurs. HCI topics in the current IT program model at the undergraduate level are presented. Finally, the authors present approaches for incorporating HCI into IT curricula.

\section{INTRODUCTION OF HCI INTO IT PROGRAM CURRICULUM}

Information Technology (IT) can be described as an integrated machine system for delivering information to provide operation, facilitation or management and decision-making [5]. In academia, the area of Information Technology is typically included as part of Management Information Systems (MIS), which Baskerville and Myers [6] see as a reference subject area, consisting of a set of components (users, hardware, software, operation, and data) that function together to create information that supports the operation and management functions of an organization. Information Technology is distinguished from Computer Science is its business orientation.

Zhang et al. [7] provided a meaningful explanation for the integration of $\mathrm{HCI}$ in IT by pointing out that Human-Computer Interaction in the Information Technology context depends on both situational context and the referent subject area being considered. Beard and Peterson [8] considered human factors in Information Technology systems to involve people, computers, and the work environment. These components are joined with human knowledge to create information technology systems enabling people to become more productive and satisfied with their working communities.

Zhang et al. [7] studied HCI by examining articles in the Management Information Systems Journal and the Journal of the Association of Information Systems. They found that in 2000-2001, approximately 32 percent of the articles where focused on HCI. Serin [9] examined a significant number of examples of poorly designed Internet interfaces from which he concluded that business and industry must pay increased attention to the usability and functionality of Information technology systems in order to not disappoint tomorrow's business consumers. The younger users of tomorrow's business systems will prefer conducting business online, and will be intolerant of unusable and/or dysfunctional systems. Software designers need to take into consideration the wide 
range of behavioral needs of people using the Internet [10].

System usability and the user's needs are expected to become a main priority for the highly experienced software designers [11]. Human computer interaction needs to be better understood in order to achieve successful implementation into IT systems. Much of the demand for the increasing integration of HCI into IT systems comes from rapidly developing industries. Analysts and software developers spend a great deal of time with users to define decision making and informational needs. Information Technology systems are very complex, forcing IT staff to develop approaches that use iterative feedback from users on the usability and functionality of the system in order to be seen as being strategic rather than operational.

\section{HuMAN COMPUTER INTERACTION TOPICS IN THE IT PROGRAM MODEL}

In this part of the study, the authors will try to demonstrate the uniqueness of the Human Computer Interaction topics relevant to the IT model program. In this subject area, it is initially important to understand the basic HCI curriculum developed by the Association for Computing Machinery, (ACM) [12]. The Association for Computing Machinery is an association of academic and practitioner computing specialists. According to the ACM, the content of computer human interaction $(\mathrm{CHI})$ curriculum includes: Context and use of computers; Application of computers; Human characteristics; Communication, language, and interaction; Computer systems and interface; Design and implementation methods; and Project presentations.

This computer human interaction curriculum includes a special interest group (SIG) on computer human interaction (CHI) that addresses its own model program [13]. This model program presents the design, evaluation, and implementation of interactive computing for users (humans) and the phenomena surrounding them. HCI researchers and educators are interested in understanding the variables, relationships and impact of technology interaction with humans within a managerial or organizational setting using empirical evidence. This understanding allows IT developers to create more usable technological systems, making IT users more productive and satisfied with their IT systems. It helps to increase organizational effectiveness, and to provide IT researchers with enhanced knowledge of how to extend and enhance user interface in the organizational context in which HCI takes place.

The HCI, from a user's point of view, is a computer user interface of the system that the user sees and works with to achieve their given tasks. The IT project managers' views and those of the users can differ a great deal from each other. To avoid any confusion, the authors of the paper treat HCI to be a broad area that includes developers and users. In their research framework, Zhang and $\mathrm{Li}$ [14] point out five components: Human, Technology, Interaction, Context, and Task where technology can be defined as including hardware, software, applications, data, information, knowledge, and support. Zhang and Li's framework can be helpful to organize HCI concepts within the IT curriculum.

\section{APPROACHES TO INCORPORATE HCI INTO IT CURRICULUM}

The authors of this paper present a brief review of the Association of Information Systems (AIS) (1997) undergraduate model program [15] and then present approaches for integrating HCI into the undergraduate IT curriculum. IT educators use the suggested undergraduate model program as a basis in creating their own educational IT curricula, and these suggested program models contain core courses which are periodically updated [16]. The approaches we suggest are helpful for integrating HCI into IT programs, and most include the following core courses from the 2005 Model Curriculum, as shown in Table I:

TABLE I: 2005 MODEL CURRICULUM CORE COURSES

\begin{tabular}{ll}
\hline $\begin{array}{l}\text { Fundamentals of Information } \\
\text { Systems }\end{array}$ & IT Hardware and Software \\
\hline $\begin{array}{l}\text { Networks and Telecommunication } \\
\text { Data, File, and Object Structures }\end{array}$ & $\begin{array}{l}\text { Programming } \\
\text { Information Systems Theory and } \\
\text { Practice with DBMS } \\
\text { Physical Design and Implementation } \\
\text { with DBMS }\end{array}$ \\
Project Management and Practice & $\begin{array}{l}\text { e-Business Strategy, Architecture, } \\
\text { and Design }\end{array}$ \\
&
\end{tabular}

The ACM model curriculum helps universities to establish their own undergraduate and graduate IT programs based on their learner population, instructor capabilities, and the needs of the local business and industry. It is expected that each educational institution can offer new options in teaching, learning, working, and technology management so students can choose a career track to pursue. The problem becomes the integration of HCI into the current IT program. New requirements must be established and old requirements modified or eliminated in order to identify core courses, and at the same time to avoid conflict regarding the number of required credit hours.

The procedure for an IT department to incorporate HCI into its undergraduate program is certainly not easy. The authors suggest a developmental approach to the integration of HCI into the IT undergraduate program. The following stages are suggested:

1) Initiate IT programs with courses that are already $\mathrm{HCI}$ focused;

2) Adapt courses such as Management Information Systems that include many managerial and human factors that can easily lend themselves to integration;

3) Create an individual course solely covering $\mathrm{HCI}$;

4) Develop an elective course in HCI to orient undergraduates, with the course developed with guidelines from outside accrediting institutions and professional associations at the national level.

5) Develop and offer different elective courses in HCI that focus on industry, interdisciplinary cooperative collaboration, and system usability.

The HCI course focusing on industrial experience would invite speakers from industry to talk about digital design content. Student projects would be presented to and judged by industry professionals.

The HCI course focusing on interdisciplinary cooperative collaboration would focus on screen design, HCI theory, and principles of graphic design. This would include 
undergraduates from graphics design, cognitive science, and business [17].

The HCI system usability course would focus on e-commerce by creating business models that connect to system design. The School of Information and Library Science at the University of North Carolina in Chapel Hill offers such an alternative graduate degree in information science. There are no similar degrees offered in the undergraduate programs. Their program focuses on the analysis of the user-centered system, user interface and human-computer interaction and it has the option of development of an individual project that relates to $\mathrm{HCI}$ context. A graphic depiction of the model is showing in the following Fig. 1.

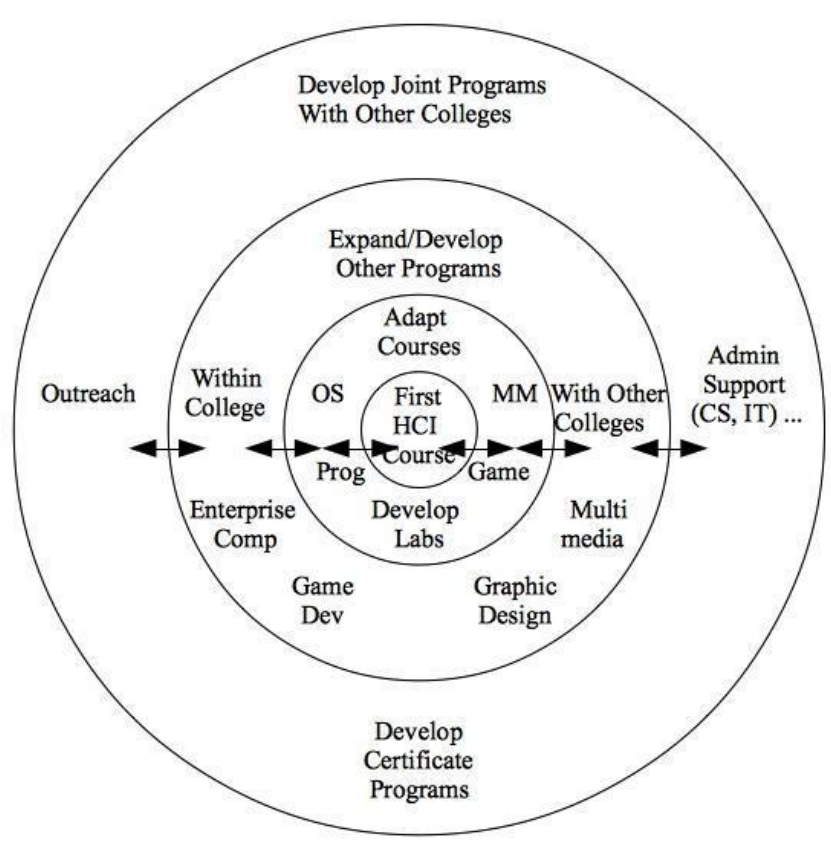

Fig. 1. Model for developing HCI in the curriculum.

\section{DEVELOPMENT OF HCI INTEGRATION INTO THE IT PROGRAM}

Instead of replacing entire courses in the IT program with HCI courses, we suggest that HCI instructional material be incorporated into the IT model course program in two possible ways: integration of HCI within a mandatory IT course, or the creation of a separate HCI course. The approach is to incorporate HCI elements into the body and instructional material of the course. The instructional materials would be about human factors and HCI segments. The HCI part of each chapter could well be at the beginning of the chapter to capture the attention of the learner and draw them into the course. It might also be beneficial or motivating to begin the chapter with a component on computer anxiety. If learners are experiencing computer anxiety, perhaps dealing with it in the beginning may help to alleviate the effect, and set the mood for a moderate, yet informative semester. The inclusion of HCI in required courses is important. Suggested candidate courses for incorporating HCI components into existing IT curricula could be Programming courses (including Web Development,
Multimedia Design, and so on), Management Information Systems, and System Analysis and Design.

\section{Programming-Oriented HCI Course}

The goal of incorporating HCI into programming courses is to train and teach future analysts and programmers. The emphasis of programming courses is on functionality, effectiveness, and syntax. Components like readability and usability were and are seldom used and taught for assessment. As a result, it is no surprise that users are often not satisfied with software products that programmers produce.

The latest language upprades for VB.NET tried to standardize the resultant generated interfaces which are considered as a positive feature, but it creates constraints for the flexibility of those interfaces that is noted as a negative feature. Software specialists need to ensure that the interfaces generated by their software are flexible and usable. Structured-programming techniques do not help guarantee usability, but only maintainability of code. There is an ongoing need for documentation to support the maintainability of code. Each programming course needs to contain at least three HCI-driven parts; the first covering HCI principles and guidelines, the second covering maintainability of code, and the third covering the usability of the coded program. HCI principles and standards need to be taught and software products should be assessed on how well the software complies with these standards.

\section{INDUSTRY-ORIENTED HCI COURSE}

The industry-oriented HCI course would be included in an undergraduate program, and would offer students the exposure to industry-focused experience in the form of presentations and seminars by guest speakers from industry. Such seminars would teach students to experience the challenges in designing interfaces for small Personal Digital Assistant (PDA) devices or mobile devices. Students would work in groups to develop and design systems, focusing on the production of new digital content for the wireless systems.

The students would create and deliver a final presentation of the design and implementation of the new system. Invited guests to these final presentations could be business people in the electronics industry, mobile Internet Service Provider (ISP), content specialists, venture capitalists, and intellectual property lawyers [18]. Venture capitalists could judge and assess the projects of the graduates and corporate sponsors could assist students to bring their creations to the market Universities can benefit from the revenue stream and the students can get excellent job opportunities right before graduation.

The interdisciplinary collaborative courses allow students from business, cognitive science studies, and graphic design to participate and gain experience in HCI courses and laboratories. Students from different cognitive sciences bring knowledge in computer science, linguistics, philosophy, psychology, neuroscience, system and cognitive engineering This understanding of human factors improves the design 
and implementation of systems that support the HCI principles. As per Michalski, Grobelny, and Karwowski [18], the course focuses on HCI theory and principles of graphic design and web-based topology.

The HCI courses can be taught to business and industry-centered audiences with both computer and non computer interests, with pedagogical techniques for delivering HCI components at different practical levels. The topics on the individual HCI course could differ based on focus and thrust of the course and different emphasis of the IT curriculum.

\section{Pedagogical ApProach in TeAChing HCI Courses}

The HCI courses demand particular pedagogical consideration when teaching at different academic levels. Various tailored pedagogical approaches for teaching HCI courses to the undergraduate students can be used including: Face-to-face teaching and discussions; HCI focused instructional material; class and online discussions; case studies; use of VB.net to create an interface design; discussion of design principles; collective decision-making, design, critique, and usability assessment project (group project) and interface design; participation in HCI research methods experiments and work; collective study, design, and peer evaluation of projects; and examinations.

\section{CONCLUSION AND DiscusSION}

This paper creates a case for the integration of HCI content in an IT model undergraduate program and suggests pedagogical approaches to teach these HCI courses. The authors believe that the lack of HCI courses in the AIS model program resulted in the production of IT graduate students that do not have sufficient understanding and knowledge of information technology design as well as the use and their work tasks. These issues, in turn, could result in information systems that are not efficient and usable. The incorporation of HCI components into IT courses provide undergraduates with industrial experience that supports the theory taught at university level. This allows more efficient communication between users and advanced technology. Focus on HCI will result in improvement of users' experience with the technology and enhancement of the usability of the future systems.

\section{REFERENCES}

[1] J. Gerlach and F. Kuo, "Understanding human-computer interaction for information systems design," MIS Quarterly, vol. 15, pp. 527-549, 1991.

[2] P. Curzon, R. Ruksenas, and A. Blandford, "An approach to formal verification of human-computer interaction," Formal Aspects of Computing, vol. 19, pp. 513 - 550, 2007.

[3] B. Santos, "An Introductory Course on Human-Computer Interaction: Program, Bibliography, Practical Classes and Assignments," Computers and Graphics, vol. 30, pp. 658-668, 2006.

[4] J. Carey, D. Galletta, J. Kim, D. Teeni, B. Wildemuth, and P. Zhang, "The role of human-computer interaction in management information systems curricula," Communications of the Association for Information Systems, vol. 13, pp. 357-379, 2004.

[5] D. Diaper and C. Sanger, "Tasks for and tasks in human-computer interaction," Interacting with Computers, vol. 18, pp. 117-138, 2006.

[6] R. Baskerville and M. Myers "Information systems as a reference discipline," MIS Quarterly, vol. 26, pp. 1-14, 2002.

[7] P. Zhang, I. Benbasat, J. Carey, F. Davis, D. Galletta, and D. Strong, "Human-computer interaction research in the MIS discipline," Communications of the Association for Information Systems, vol. 9, pp. 334-355, 2002.

[8] J. Beard and T. Peterson, "Taxonomy for the study of human factors in management information systems," in J. Carey, ed., Human Factors in Management Information Systems, Greenwich, CT: Ablex Publishing Corporation, 1988, pp. 7-26

[9] O. Serin, "The effects of the computer-based instruction on the achievement and problem solving skills of the science and technology students," The Turkish Online Journal of Educational Technology, vol 10, pp. $183-201,2011$.

[10] J. Raskin, The Humane Interface: New Directions for Designing Interactive Systems, Boston, MA: Addison Wesley Longman, 2000.

[11] V. Venkatesh, M. Moris, G. Davis, and F. Davis, "User acceptance of information technology: Toward a unified view," MIS Quarterly, vol. 27, pp. 425-475, 2006.

[12] ACM and IEEE Computer Society. Computing curricula 2005 computer Science. Report of the ACM/IEEECS joint task force on computing Curricula. [Online]. Available: http://www.computer.org/education/cc2005/final/index

[13] T. Hewett, R. Baecker, C. Carey, J. Gasen, M. Mantei, G. Perlman, J. Strong, and W. Verplank. (2006). ACM, SIGCHI Curricula for human computer interaction. [Online]. Available: http://www.sigchi.org/cdg/cdg2.html\#2_1

[14] P. Zhang and N. Li, "An assessment of human-computer interaction research in management information systems," Computers in Human Behavior, vol. 20, pp. 125-147, 2004

[15] M. Lichtman, Qualitative research in education, a user's guide, Sage Publications, 2006, USA.

[16] J. Gorgone, G. Davis, J. Valacich, H. Topi, D. Feinstein, and H. Longenecker. (2002). Model curriculum and guidelines for undergraduate degree programs in information systems. Association for Information Systems. [Online]. Available: http://www.acm.org/education/is2002.pdf

[17] H. Beyer and K. Holtzblatt, Contextual design, San Francisco: Morgan Kaufman, 1998

[18] R. Michalski, J. Grobelny, and W. Karwowski, "The effects of graphical interface design characteristics on human-computer interaction task efficiency," International Journal of Industrial Ergonomics, vol. 36, pp. 959-977, 2006.

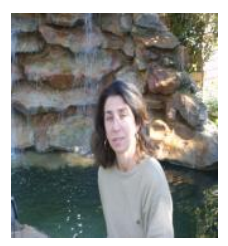

Anrieta Draganova received her Doctorate of Science degree in Electrical Engineering from the George Washington University in Washington DC, USA in 1992. She earned her Master of Science degree in Electrical Engineering from the George Washington University in Washington DC, USA in 1987. Dr Draganova's professional life was always focused on teaching undergraduate and graduate students in the United States of America, Asia, and Europe. Her research interest is about connecting academia and professional real life.

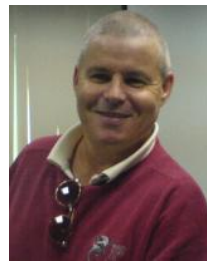

Patrick Doran earned a BBA from the University of New Brunswick, Fredericton, NB., Canada in 1986 and a Ph.D. in management information systems from the Terry College of Business of the University of Georgia, Athens, GA. USA in 1992. He has worked at Oklahoma City University, Saint Marys University (Canada), Hawaii Pacific University, University of New Brunswick, and Zayed University in Abu Dhabi. Current his research interests are in educational technology, cultural effects and issues, and curriculum development.

Dr. Doran has been named to Who's Who Among America's Teachers three times and has twice been named Exemplary Professor at Zayed University. 